\title{
Gastrointestinal stromal tumor mesenchymal neoplasms: the offspring that choose the wrong path
}

This article was published in the following Dove Press journal:

Journal of Multidisciplinary Healthcare

3 April 2013

Number of times this article has been viewed

\author{
Nikolaos Machairiotis' \\ loanna Kougioumtzi' \\ Paul Zarogoulidis ${ }^{2}$ \\ Aikaterini Stylianaki \\ Konstantinos Tsimogiannis ${ }^{3}$ \\ Nikolaos Katsikogiannis' \\ 'Surgery Department (National \\ Health System), University General \\ Hospital of Alexandroupolis, \\ Alexandroupolis, ${ }^{2}$ Pulmonary \\ Department - Oncology Unit, "G \\ Papanikolaou" General Hospital, \\ Aristotle University of Thessaloniki, \\ Thessaloniki, ${ }^{3}$ Department of Surgery, \\ G Hatzikosta General Hospital of \\ loannina, loannina, Greece
}

\begin{abstract}
Gastrointestinal stromal tumors (GISTs) are relatively rare neoplasms of the gastrointestinal tract originating from the pluripotential mesenchymal stem cells, which differentiate into interstitial Cajal cells. They are usually located in the upper gastrointestinal track. These tumors are typically defined by the expression of c-KIT (CD117) and CD34 proteins in the tumor cells. A small percentage of these tumors is negative for c-KIT. The neoplasms are positive for platelet-derived growth factor $\alpha$ (PDGF $\alpha$ ) mutations. In addition to PDGFR $\alpha$ mutations, wild-type c-KIT mutations can also be present. The therapeutic approach to locally developed gastrointestinal stromal tumors is surgical resection, either with open or laparoscopic surgery. In case of systemic disease, molecular pharmacologic agents such as imatinib and sunitinib are used for treatment. These agents block the signaling pathways of neoplastic-cell tyrosine kinases, interfering in their proliferation and causing apoptosis.
\end{abstract}

Keywords: GIST, mesenchymal stem cells, cancer pathways, interstitial cells of Cajal, $\operatorname{PDGFR} \alpha$

\section{Introduction}

Gastrointestinal stromal tumors (GISTs) are rare mesenchymal neoplasms of the gastrointestinal tract originating from pluripotential mesenchymal stem cells, which differentiate into the interstitial Cajal cells. ${ }^{1}$ GISTs are mesenchymal cancer cells of the gastrointestinal tract. They are usually located in the upper gastrointestinal tract - more specifically, in the stomach (60\%); GISTs of the small bowel $(30 \%)$, esophagus $(5 \%)$, and rectum $(5 \%)$ are less common. ${ }^{1,2}$ The clinical presentation of GISTs is heterogeneous. The most common symptoms are bleeding from the upper gastrointestinal tract and abdominal pain, but there is a significant percentage of GISTs that remain asymptomatic and are discovered incidentally. ${ }^{3}$

\section{Role of c-KIT and platelet-derived growth factor $\alpha$ (PDGFR $\alpha)$}

GISTs are defined by the expression of c-KIT (CD117) and CD34 proteins in cancer cells. ${ }^{4}$ The c-KIT oncogene is located on chromosome $4 .{ }^{5}$ The remaining $3 \%-5 \%$ of c-KIT-negative GISTs are positive for PDGFR $\alpha$ mutations. In addition to PDGFR $\alpha$ mutations there is a small percentage of wild-type c-KIT mutations. ${ }^{6,7}$ The oncogenic mutations in the $c$-KIT gene are located on exons 9, 11, 13, and $17 .^{8,9}$ It is known that the most common mutations on exon 11 are deletions and substitutions, with duplications and insertions less common. Additionally, the mutation in codon 558 in $5^{\prime} \mathrm{KIT} .{ }^{10}$ As far as PDGFR $\alpha$ is concerned, the muta-
Correspondence: Paul Zarogoulidis Pulmonary Department,

"G Papanikolaou" General Hospital, Aristotle University of Thessaloniki, Thessaloniki, Greece

Tel +3023 I 0992432

$\mathrm{Fax}+3023$ I 0992433

Email pzarog@hotmail.com 
tions are located on exons 12,14 , and 18 . It is crucial to note that both c-KIT and PDGFR $\alpha$ expression induce a tyrosine kinase pathway in the cancer cell. ${ }^{10}$ Activation of this pathway induces uncontrolled phosphorylation and tissue growth. ${ }^{11}$

The most common secondary resistance mechanism seems to be mutation of the KIT kinase domain. The exact locations of the mutation are the adenosine triphosphate (ATP) binding pocket of the KIT kinase (exons 2, 3) and the kinase activation loop. Additionally, imatinib-resistant KIT exon 9 or PDGFR $\alpha$ exon 18 D842V mutations - or even no detectable mutation at all - could be the cause of the resistance. ${ }^{12,13}$ It is also important that secondary mutations located on KIT exon 11 can cause low response to imatinib treatment. ${ }^{14-18}$ Taking into consideration the fact that in $5 \%-15 \%$ of GISTs these mutations are absent, scientists consider it possible that there is an additional pathway that has not yet been discovered. ${ }^{11}$

\section{Treatment}

GISTs are malignant neoplasms and therefore tumor prognostic factors are extremely important. The most important prognostic factors are size $>5 \mathrm{~cm}$, mitotic activity (mitotic count $>1-5$ per ten high-powered fields), diffuse moderate atypia, and coagulation necrosis. ${ }^{19,20}$ Recently, mutations in the $c-K I T$ oncogene were added to these criteria.

Although improvements in understanding of the molecular pathways responsible for the pathogenesis of GISTs improved have resulted in impressive advances in targeted therapy, surgical resection of the tumor with preservation of the pseudocapsule remains the preferred therapy for localized GISTs. ${ }^{21}$ GISTs do not metastasize through lymphatic spread, so there is no indication for systemic lymph-node resection. ${ }^{22}$ Surgical treatment can be either laparoscopic or even endoscopic in case of patients who cannot be operated on or in patients with very small GISTs $(<2 \mathrm{~cm}) .{ }^{23}$ Surgery is used in three main situations: primary surgery after diagnosis, especially in solitary tumors; after neoadjuvant treatment; ${ }^{24}$ or, occasionally, for symptomatic relief in advanced metastatic disease (termed "debulking surgery"). ${ }^{21}$ Poor response is usually observed following conventional chemo- and radiation therapy. ${ }^{21}$

Since Hirota et al observed the role of c-KIT in GIST, scientists have found agents that inhibit the molecular pathway of the oncogene proteins. ${ }^{4}$ The pharmaceuticals imatinib and sunitinib have been used. Drugs bind (with active targeting) and inhibit the phosphorylation and downstream of KIT signaling activation (Table 1). ${ }^{11,21,25}$ Imatinib binds within the ATP binding pocket and the activation loop. ${ }^{21}$ Consequently, inhibition of auto-phosphorylation and inhibition of downstream signaling pathways - such as mitogen-activated protein kinase (MAPK) and AKT (protein kinase B) - take place ${ }^{2}$ (Figure 1). Sunitinib interacts with different amino acids within the ATP binding pocket. ${ }^{21}$ Disease progression is a result of c-KIT mutations on exons 13,14 , and 17, which decrease the tumor's sensitivity to imatinib and additional chemotherapy. ${ }^{11,26-29}$

The protocols used for the treatment of GISTs are based on their biological behavior. More specifically, surgical resection is the golden standard therapy for localized tumors without systematic metastases and without high-risk tumor features, such as cystic space, ulceration, echogenic foci, and irregular borders. ${ }^{25,30}$ Neoadjuvant therapy can be used in cases of patients with marginally resectable tumors and in whom surgery is contraindicated. The European Society for Medical Oncology (ESMO) guidelines advocate tumor debulking in order to facilitate total tumor resection. Imatinib is the drug used in adjuvant and neoadjuvant therapy; in case of resistance in imatinib, sunitinib is used. ${ }^{31}$ Unfortunately, therapeutic options are limited in progressive disease.

There is a general agreement that when GISTs are smaller than $2 \mathrm{~cm}$ and are located in the upper gastrointestinal tract (esophagus, stomach, duodenum), laparoscopic ultrasound should be performed and subsequently followed-up. ${ }^{32}$ For nodules larger than $2 \mathrm{~cm}$, a biopsy should be conducted and after that a total tumor excision if the diagnosis of GIST is made. There is also an indication for biopsy of the primary lesion of any size if neoadjuvant therapy is planned, or if there are sites suspicious for tumor metastasis. Additionally, in cases when multi-visceral resection is to be performed, biopsies are considered important. As far as rectal GISTs are concerned, the standard diagnostic and therapeutic approach includes endoscopic ultrasound, magnetic resonance imaging assessment, biopsy, and wide excision.

Tumor management is strongly related to the stage of the disease. As mentioned, determination of tumor size, mitotic count, and mutation analysis of the $c$-KIT gene are considered crucial for the diagnosis of this neoplasm. Also as noted previously, the golden standard therapy for primary localized GISTs is complete surgical resection - with negative margins (R0) without resection of negative lymph nodes. In cases of intermediate and high-risk GIST, according to National Comprehensive Cancer Network guidelines, ${ }^{32} \mathrm{R} 0$ tumor resection should be followed by adjuvant therapy with imatinib for at least 1 year. In contrast, the revised ESMO 


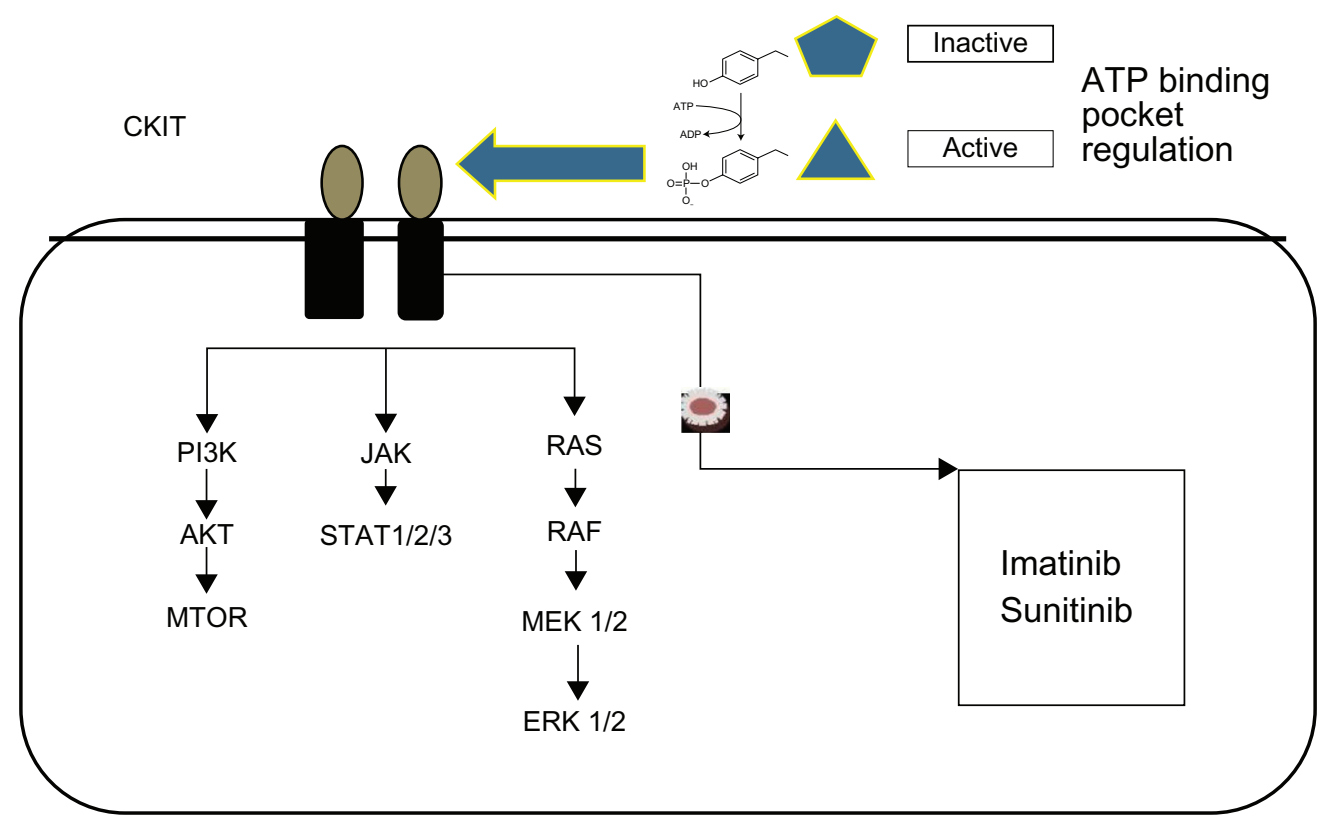

Figure I Targeted therapy pathways.

Notes: Protein kinase B (AKT) is a serine/threonine-specific protein kinase that affects glucose metabolism, apoptosis, cell proliferation, transcription and cell migration. Together, RAS, c-RAF, MEK I/2, RAS, and ERK I/2 comprise the MAPK-ERK pathway, which is a chain of proteins in the cell that communicates a signal from a receptor on the surface of the cell to the DNA in the nucleus of the cell; it is also known as the "Ras-Raf-MEK-ERK pathway." Janus kinase (JAK) is a family of intracellular, non-receptor tyrosine kinases that transduce cytokine-mediated signals via the JAK-STAT pathway. Phosphoinositide 3-kinase (PI3K) is an important signaling pathway for growth control, metabolism, and translation initiation. The active sites of tyrosine kinases each have a binding site for adenosine triphosphate (ATP).

Abbreviations: ERK, extracellular signal-regulated kinases; MAPK, mitogen-activated protein kinases; MTOR, mammalian target of rapamycin; STAT, signal transducer and activator of transcription.

guidelines for GIST therapy propose adjuvant therapy with imatinib only in cases where there is a substantial risk of relapse and no adjuvant therapy in cases with low or very low risk of recurrence. In case of complete resection with positive margins (R1), re-excision should be performed if it is possible. If this approach is not possible, the patient is placed under observation. Preoperative imatinib may be useful in cases in which negative margins are not easy to obtain, therefore multi-visceral resection is indicated and the operating time should be optimized. In these cases, neoadjuvant therapy that lasts $6-12$ months is desirable. ${ }^{32}$

Table I Clinical trials of imatinib

\begin{tabular}{lll}
\hline Trial & Progression-free survival & Overall survival \\
\hline NCT0004II97 & I year & \\
EORTC 62005 & $\begin{array}{l}44 \% \text { of the } 400 \mathrm{mg} \text { group } \\
50 \% \text { of the } 800 \mathrm{mg} \text { group }\end{array}$ & $\begin{array}{l}400 \mathrm{mg} \text { I year, } 62 \% \text { at } 2 \text { years } \\
800 \mathrm{mg} \text { group: } 86 \% \text { at }\end{array}$ \\
& & $\begin{array}{l}\text { I year, } 74 \% \text { at } 2 \text { years } \\
\text { B2222 }\end{array}$ \\
& $\begin{array}{l}24 \text { months (20 months } \\
\text { in the } 400 \mathrm{mg} \text { group and }\end{array}$ & 57 months \\
& $\begin{array}{l}26 \text { in the } 600 \text { mg group) } \\
\text { I8 months in the } 400 \mathrm{mg}\end{array}$ & 55 and 5 I months \\
& $\begin{array}{l}\text { group and } 20 \text { months } \\
\text { in the } 800 \mathrm{mg} \text { group }\end{array}$ & \\
\hline
\end{tabular}

Abbreviations: EORTC, European Organisation for Research and Treatment of Cancer; SWOG, Southwest Cancer Chemotherapy Study Group.
In case of locally advanced, inoperable, or metastatic disease, the standard therapeutic strategy is $400 \mathrm{mg}$ imatinib daily. In patient groups who are positive for exon 9 mutations, which provoke tolerance to imatinib, the dose of the drug is doubled to $800 \mathrm{mg}$ daily. It is crucial that the therapy not be interrupted or stopped for a long period, because this can result in a poor therapy response or even disease recurrence. In patients for whom imatinib is not effective, sunitinib is the therapy of choice. ${ }^{32}$

\section{Studies on imatinib}

The Scandinavian Sarcoma Group (SSG) XVIII trial (unpublished data) compared 12 and 36 months' use of $400 \mathrm{mg}$ imatinib daily in 400 patients with high-risk resected GIST. The definition of "high risk" was made according to the previously mentioned modified consensus criteria. The trial contained a median follow-up of 54 months, in which prolonged treatment was associated with a significant improvement in relapse-free survival (RFS) (5-year RFS 66\% vs $48 \%$, hazard ratio [HR] $0.46,95 \%$ confidence interval [CI] $0.32-0.65)$ as well as overall survival ( $92 \%$ vs $82 \%$, HR 0.45 , $85 \%$ CI 0.22-0.89). Additionally, the study demonstrated that treatment-related adverse effects were more common with longer treatment. These adverse effects included periorbital 
edema, diarrhea, and muscle cramps. These effects were noted in patients with grade 1 or 2 tumors; there was no significant difference between the two groups in terms of the number of adverse effects occurring in patients with grade 3 or 4 GISTs. In the prolonged therapy group, patients' compliance to the therapy was not satisfactory. Overall, the study data indicate that 36 months' use of imatinib is important for patients with high-risk GISTs.

The BFR14 trial was conducted to study the effects of interruption to imatinib therapy. ${ }^{33}$ In this study, 71 patients without disease progression were randomized after 1 (32 patients), 3 (25 patients), and 5 (14 patients) years of interruption to daily $400 \mathrm{mg}$ imatinib mesylate therapy. In case of disease progression, imatinib was reintroduced. The results of the study showed that imatinib interruption in responding patients with advanced GIST cause disease progression in the majority of these patients. ${ }^{33}$

The Radiation Therapy Oncology Group study ${ }^{34}$ found that patients with metastatic disease and locally advanced disease seem to respond well to the use of imatinib postoperatively. Sixty-three patients were entered into this study, of whom 52 were analyzable - 30 with primary GIST (group A) and 22 with metastatic GIST (group B). The therapy response (according to the Response Evaluation Criteria In Solid Tumors [RECIST] rules) in group A was 7\% partial, $83 \%$ stable, and $10 \%$ unknown and, in group B, $4.5 \%$ partial, $91 \%$ stable, and $4.5 \%$ progression. Two-year progression-free survival was $83 \%$ in group A and $77 \%$ in group B. The estimated overall survival was $93 \%$ in group A and $91 \%$ in group B. ${ }^{34}$

Table 1 summarizes the findings of four imatinib trials.

\section{Conclusion}

GISTs are malignant tumors of the gastrointestinal tract that have been thoroughly studied over the past few years. Once the molecular pathways and the mutations that are responsible for them began to be understood, there was great progress made in GIST treatments. Aside from surgical resection, which was and continues to be the gold standard treatment for non-metastatic GISTs, progress has been made in the development of systematic treatment using special pharmacologic agents, such as imatinib and sunitinib, that intervene in the molecular pathways responsible for the GIST pathogenesis. This has provided practitioners the opportunity to heal patients with metastatic GISTs.

In future, there is potential for new molecular inhibitors with activity comparable to that of imatinib to be developed for GIST therapy. Another important field of interest is identification of the mutations responsible for reduced response to imatinib. As in chronic myelogenous leukemia, these could be used to develop new agents that act on the mutation locations.

\section{Disclosure}

The authors declare no conflicts of interest in this work.

\section{References}

1. Kindblom LG, Remotti HE, Aldenborg F, Meis-Kindblom JM. Gastrointestinal pacemaker cell tumor (GIPACT): gastrointestinal stromal tumors show phenotypic characteristics of the interstitial cells of Cajal. Am J Pathol. 1998;152(5):1259-1269.

2. Blay JY. A decade of tyrosine kinase inhibitor therapy: Historical and current perspectives on targeted therapy for GIST. Cancer Treat Rev. 2011;37(5):373-384.

3. De Vogelaere K, Hoorens A, Haentjens P, Delvaux G. Laparoscopic versus open resection of gastrointestinal stromal tumors of the stomach. Surg Endosc. Epub December 12, 2012.

4. Hirota S, Isozaki K, Moriyama Y, et al. Gain-of-function mutations of c-kit in human gastrointestinal stromal tumors. Science. 1998; 279(5350):577-580.

5. Badalamenti G, Rodolico V, Fulfaro F, et al. Gastrointestinal stromal tumors (GISTs): focus on histopathological diagnosis and biomolecular features. Ann Oncol. 2007;18 Suppl 6:vi136-vi140.

6. Bai CG, Hou XW, Wang F, et al. Stem cell factor-mediated wild-type KIT receptor activation is critical for gastrointestinal stromal tumor cell growth. World J Gastroenterol. 2012;18(23):2929-2937.

7. Lamba G, Ambrale S, Lee B, Gupta R, Rafiyath SM, Liu D. Recent advances and novel agents for gastrointestinal stromal tumor (GIST). J Hematol Oncol. 2012;5:21.

8. Wong NA, Deans ZC, Ramsden SC. The UK NEQAS for Molecular Genetics scheme for gastrointestinal stromal tumour: findings and recommendations following four rounds of circulation. J Clin Pathol. 2012;65(9):786-790.

9. Suzuki K, Kaneko G, Kubota K, et al. Malignant tumor, of the gastrointestinal stromal tumor type, in the greater omentum. J Gastroenterol. 2003;38(10):985-988.

10. Lasota J, Kuban W, Wardelmann E, et al. KIT codon 558 insertions in gastrointestinal stromal tumors. Analysis of 17 rare KIT mutants. Hum Pathol. 2008;39(12):1728-1736.

11. Gramza AW, Corless CL, Heinrich MC. Resistance to Tyrosine Kinase Inhibitors in Gastrointestinal Stromal Tumors. Clin Cancer Res. 2009; 15(24):7510-7518.

12. Debiec-Rychter M, Dumez H, Judson I, et al; EORTC Soft Tissue and Bone Sarcoma Group. Use of c-KIT/PDGFRA mutational analysis to predict the clinical response to imatinib in patients with advanced gastrointestinal stromal tumours entered on phase I and II studies of the EORTC Soft Tissue and Bone Sarcoma Group. Eur J Cancer. 2004;40(5):689-695.

13. Heinrich MC, Corless CL, Demetri GD, et al. Kinase mutations and imatinib response in patients with metastatic gastrointestinal stromal tumor. J Clin Oncol. 2003;21(23):4342-4349.

14. Antonescu CR, Besmer P, Guo T, et al. Acquired resistance to imatinib in gastrointestinal stromal tumor occurs through secondary gene mutation. Clin Cancer Res. 2005;11(11):4182-4190.

15. Heinrich MC, Corless CL, Blanke CD, et al. Molecular correlates of imatinib resistance in gastrointestinal stromal tumors. J Clin Oncol. 2006;24(29):4764-4774.

16. Wardelmann E, Thomas N, Merkelbach-Bruse S, et al. Acquired resistance to imatinib in gastrointestinal stromal tumours caused by multiple KIT mutations. Lancet Oncol. 2005;6(4):249-251.

17. Desai J, Shankar S, Heinrich MC, et al. Clonal evolution of resistance to imatinib in patients with metastatic gastrointestinal stromal tumors. Clin Cancer Res. 2007;13(18 Pt 1):5398-5405. 
18. Nishida T, Kanda T, Nishitani A, et al. Secondary mutations in the kinase domain of the KIT gene are predominant in imatinib-resistant gastrointestinal stromal tumor. Cancer Sci. 2008;99(4):799-804.

19. Miettinen M, Sobin LH, Lasota J. Gastrointestinal stromal tumors of the stomach: a clinicopathologic, immunohistochemical, and molecular genetic study of 1765 cases with long-term follow-up. Am J Surg Pathol. 2005;29(1):52-68.

20. Sobin LH, Compton CC. TNM seventh edition: what's new, what's changed: communication from the International Union Against Cancer and the American Joint Committee on Cancer. Cancer. 2010;116(22): 5336-5339.

21. Tan CB, Zhi W, Shahzad G, Mustacchia P. Gastrointestinal stromal tumors: a review of case reports, diagnosis, treatment, and future directions. ISRN Gastroenterol. 2012;2012:595968.

22. DeMatteo RP, Lewis JJ, Leung D, Mudan SS, Woodruff JM, Brennan MF. Two hundred gastrointestinal stromal tumors: recurrence patterns and prognostic factors for survival. Ann Surg. 2000;231(1): 51-58.

23. Jeong IH, Kim JH, Lee SR, et al. Minimally invasive treatment of gastric gastrointestinal stromal tumors: laparoscopic and endoscopic approach. Surg Laparosc Endosc Percutan Tech. 2012;22(3):244-250.

24. Karanikas M, Machairiotis N, Zarogoulidis P, et al. Non-Hodgkin lymphoma and GIST: molecular pathways and clinical expressions. Onco Targets Ther. 2012;5:433-438.

25. Sepe PS, Brugge WR. A guide for the diagnosis and management of gastrointestinal stromal cell tumors. Nat Rev Gastroenterol Hepatol. 2009;6(6):363-371.

26. Wang D, Zhang Q, Blanke CD, et al. Phase II trial of neoadjuvant/ adjuvant imatinib mesylate for advanced primary and metastatic/ recurrent operable gastrointestinal stromal tumors: long-term follow-up results of Radiation Therapy Oncology Group 0132. Ann Surg Oncol. 2012;19(4):1074-1080.
27. Blanke CD, Rankin C, Demetri GD, et al. Phase III randomized, intergroup trial assessing imatinib mesylate at two dose levels in patients with unresectable or metastatic gastrointestinal stromal tumors expressing the kit receptor tyrosine kinase: S0033. J Clin Oncol. 2008;26(4):626-632.

28. Verweij J, Casali PG, Zalcberg J, et al. Progression-free survival in gastrointestinal stromal tumours with high-dose imatinib: randomised trial. Lancet. 2004;364(9440):1127-1134.

29. Dematteo RP, Ballman KV, Antonescu CR, et al. Adjuvant imatinib mesylate after resection of localised, primary gastrointestinal stromal tumour: a randomised, double-blind, placebo-controlled trial. Lancet. 2009;373(9669):1097-1104.

30. Palazzo L, Landi B, Cellier C, Cuillerier E, Roseau G, Barbier JP. Endosonographic features predictive of benign and malignant gastrointestinal stromal cell tumours. Gut. 2000;46(1):88-92.

31. Andtbacka RH, Ng CS, Scaife CL, et al. Surgical resection of gastrointestinal stromal tumors after treatment with imatinib. Ann Surg Oncol. 2007;14(1):14-24.

32. Strong VE, D'Amico TA, Kleinberg L, Ajani J. Impact of the 7th Edition AJCC staging classification on the NCCN clinical practice guidelines in oncology for gastric and esophageal cancers. J Natl Compr Canc Netw. 2013;11(1):60-66.

33. Patrikidou A, Chabaud S, Ray-Coquard I, et al; for the French Sarcoma Group. Influence of imatinib interruption and rechallenge on the residual disease in patients with advanced GIST: results of the BFR14 prospective French Sarcoma Group randomised, phase III trial. Ann Oncol. Epub November 21, 2012.

34. Eisenberg BL, Harris J, Blanke CD, et al. Phase II trial of neoadjuvant/ adjuvant imatinib mesylate (IM) for advanced primary and metastatic/ recurrent operable gastrointestinal stromal tumor (GIST): early results of RTOG 0132/ACRIN 6665. J Surg Oncol. 2009;99(1):42-47.
Journal of Multidisciplinary Healthcare

\section{Publish your work in this journal}

The Journal of Multidisciplinary Healthcare is an international, peerreviewed open-access journal that aims to represent and publish research in healthcare areas delivered by practitioners of different disciplines. This includes studies and reviews conducted by multidisciplinary teams as well as research which evaluates the results or conduct of such teams or

\section{Dovepress}

healthcare processes in general. The journal covers a wide range of areas and welcomes submission from practitioners at all levels, from all over the world. The manuscript management system is completely online and includes a very quick and fair peer-review system. Visit http://www.dovepress.com/testimonials.php to read real quotes from published authors. 